\title{
露天铁矿采矿生产中相关问题的探讨
}

奕辉 熊宏启 范晓明 崔志平 鞍钢集团鞍千矿业有限责任公司

DOI:10.32629/gmsm.v1i3.47

[摘 要] 随着科学技术的进步,各行业的生产水平得到了很大的提升,特别是在经济建设快速发展的情况下,对各项资源的需 求量也在不断提升, 而铁矿资源是经济建设的重要组成部分,其能否进行安全、高效的开采,与社会发展需求具有非常密切的关 联。但随着铁矿开采数量的增多以及开采技术的革新,生产过程中各项问题也变得越来越复杂、多样, 如果不能对其进行有效 的防控,会对资源开采工作的顺利实施造成严重的影响, 甚至会威胁到工作人员的人身安全, 因此, 本文围绕露天铁矿生产当中 的各项问题进行深入的研究,对问题的产生原因及后果加以了解,并对各项问题的防控措施进行具体论述。

[关键词] 露天铁矿; 采矿生产; 相关问题

随着经济的增长, 我国的工业化进程也在不断推进, 在 资源方面具有较高的开发利用需求。对矿产资源加强开发和 利用, 不仅能够推动国民经济的增长, 使人们生活质量得到 有效的提升, 还能进一步的增强矿产资源的开发力度。但在 露天矿山当中, 其采矿生产往往会受到各种因素的影响, 包 括自然因素、人为因素等等, 对其安全生产、稳定生产目标 的实现造成了很大的阻碍, 所以需要对此类问题保持高度的 重视。对矿山生产加强管理, 通过有效的预防, 对矿山生产当 中的危险因素进行有效的防控, 从而降低安全风险, 确保矿 山的安全生产。

\section{1 露天铁矿采矿生产问题的产生原因及后果}

在对露天铁矿进行开采的过程中, 往往需要用到一些大 型设备进行生产作业, 且该项作业活动具有较高的自动化水 平和专业化水平, 人员方面的需求相对较少, 但如果在实际 采矿生产过程中, 不能对铁矿作业特点加以了解, 容易造成 管理缺陷问题, 进而在采矿生产当中埋下巨大的安全隐患, 影响生产活动的顺利开展。

1.1 采装运输事故

在露天铁矿开采中, 采装运输是一项较为关键的生产工 序。该项工序的工作量相对较大, 能够在整个采矿工程当中 占据 $50 \%$ 以上的比重, 通常情况下, 在露天采矿过程中, 会对 电铲挖掘机加以使用, 以此来完成装矿等工作, 且相关装载 运输设备比较高大, 加上车辆来往频繁, 运输密度较高, 车辆 载重量大, 受到工作环境等因素的影响, 司机在工作过程中 经常会出现视野盲区, 在一定程度上加大了事故的发生概率, 致使交通事故及机械伤害问题等频繁出现。

而造成上述问题的主要原因有以下几点: 第一, 工作人 员未能对安全工作进行有效的落实, 各项防护措施落实不到 位; 第二, 未能严格按照矿场道路设计的相关规定对运输道 路进行合理的规划, 存在运输道路曲率半径不合格的问题; 第三, 未能根据气候变化, 在雨季或冰雪季节落实道路防滑 措施; 第四, 部分司机存在违规操作或无证驾驶的问题; 第 五, 设备工作状态不佳, 部分安全装置失效; 第六, 挖掘机在
工作过程中存在底部超挖或采矿不均匀的问题, 对不符合规 定的大块矿石进行铲装, 使用铲斗对工作面当中的伞岩、浮 石进行挑挖或冲砸; 第七, 在运行过程中对车斗进行举升操 作, 或在临时维修期间, 没有加以设置警示牌; 第八, 使用运 矿车对爆炸器材或人员进行装载; 第九, 卸矿场没有设置相 应的阻车设施, 且卸矿工作缺乏专业人员指挥 ${ }^{[1]}$ 。

通常采装运输事故具有突发性的特点, 可能会在车辆运 行期间由于路面因素或司机因素造成车辆碰撞或侧翻等事 故, 在卸矿场进行卸矿操作时, 如果不能进行合理的指挥、使 用, 也会因为溜车等问题, 造成设备损坏或人员伤亡等问题。

\section{2 触电事故}

在露天铁矿当中应用的设备都会设置相应的操作开关, 在落实检查维修等工作时, 存在较高的触电风险。

触电事故的产生容易造成电气火灾, 威胁生产设备及操 作人员的安全, 而这种事故主要是因为工作人员未能做好防 触电措施; 电气设备在设计方面缺乏合理性, 存在安装缺陷 或在运行期间容易出现接触不良、过载、短路以及漏电等问 题; 用电场所及相关电气设备没有落实防雷接地措施; 电气 设备运行或实际操作中出现电火花; 工作人员存在操作失误 或违规操作的问题, 在断电维修过程中, 没有做好开关加锁 工作, 且未设置专人进行看管, 从而出现送电行为造成触电 事故 ${ }^{[2]}$ 。

\section{3 爆破事故}

在露天铁矿生产中, 往往会使用爆破材料, 在爆破过程 中, 可能会出现大块飞石或意外爆炸等问题, 非常容易对相 关财产及工作人员造成损害。

而造成上述事故的原因主要有以下几种: 第一, 爆破人 员专业能力不足, 没有经过专业培训, 未能严格按照相关规 定要求进行各项操作; 第二, 未按设计要求对炮孔进行施工, 导致孔内存水、卡孔以及乱孔等问题频繁出现; 第三, 爆破 之前未能做好严格的警戒, 且信号不明确, 在爆破区域未能 设置岗哨和明显标志; 第四, 爆破区域中的设备及构筑物缺 乏保护措施, 或爆破器材未经检验, 存在质量不合格问题, 对 
于盲炮处理不及时或处理方法不当, 爆破操作没有根据爆破 说明进行; 第五, 在气候条件不佳的情况下进行爆破, 包括大 雾天气、大风天气以及雷雨天气等; 第六, 在遇到特殊情况 时, 未能将爆破作业及时停止, 对电力起爆规程缺乏了解, 导 致杂散电流对起爆造成影响, 引发早爆事故; 第七, 采场当中 没有设置相应的避炮设施。

露天铁矿当中的爆破作业具有较高的爆炸能量, 且爆炸 范围较广, 如果不能对相关防护措施进行有效的落实, 容易 产生噪声、地震波以及冲击波, 对周围的设备、人员以及构 筑物造成威胁, 特别是在涉及人员时, 其事故后果往往都比 较严重 ${ }^{[3]}$ 。

\section{4 采场边坡事故}

露天铁矿通常具有较大的开采深度, 其最终边坡具有较 长的保留时间, 但在实际生产过程中, 会因为一些不利因素 的影响, 降低边坡的稳定性, 如出现降雨或冰雪天气等, 一旦 出现破碎或断层问题, 会在边坡当中产生各种形式的破坏, 对工作人员的安全以及采矿工作的正常进行造成影响 ${ }^{[4]}$ 。

如果在对露天铁矿的边坡进行设计时, 不能对各项参数 进行合理的选择, 非常容易产生滑坡问题, 特别是在雨季, 还 可能会造成泥石流等灾害, 与此同时, 如果不能对安全平台 进行合理的预留, 或者安全平台当中的浮石未能进行及时的 清理, 会加大滚石打击的产生概率, 在边坡附近进行爆破操 作, 若没有及时设置防爆破措施, 容易造成边坡垮塌, 在开采 过程中, 如果没有根据设计要求运用台阶式的开采方式, 非 常容易出现局部矿岩不稳定的问题。

这些问题如果不能进行有效的防控, 不但会对采矿工作 方面造成影响, 还可能会对设备及人员造成掩埋, 产生重大 安全事故。

\section{5 排土场事故}

对于露天铁矿而言, 通常需要对外部培土场加以建设, 但由于其具有较大的堆筑高度, 如果设计和管理工作缺乏规 范性, 非常容易造成泥石流、滑坡以及环境污染等问题。

这种问题主要是因为工作过程中未能对培土场中的安 全因素进行有效的排查与监控, 从而在遇到外部因素影响时, 产生安全事故 ${ }^{[5]}$

\section{2 防范露天铁矿采矿生产问题的有效措施}

2.1 对矿床地质加强研究

要针对露天铁矿当中的资源总量及数量加强调查, 并对
铁矿矿山加强数字化建设, 通过对相关高新技术的有效应用, 构建矿山地质数据库, 使矿床地质研究工作得到有效的强化, 并通过信息资源及网络的有效管理, 对矿山当中的生产设 计、管理调度以及资源配置加强数字化建设, 以此来保证各 项矿山开采工作的有序开展 ${ }^{\left[{ }^{[}\right]}$。

\section{2 对矿床地质加强稳产研究}

要对多学科进行有效应用, 借助极限平衡理论以及有限 差分法, 对矿床使用过程中的坡面角进行合理的设计, 并通 过陡坡运输技术、集成电子技术以及边坡问题检测的有效研 究, 使露天铁矿中的边坡岩能够得到实时的监控, 确保各项 防控措施的及时应用。

\section{3 对充填采矿方法加强应用}

通过对该项技术的研发与应用, 能够使矿产资源获得更 高的开发利用率, 并且对废弃岩石的有效利用, 能够提升开 采操作的环保水平, 而顶柱深孔预留爆破岩石技术作为填充 采矿方法的主要内容, 较为注重人和自然之间的协调性, 能 够有效降低露天铁矿开采对周围环境的影响 ${ }^{[7]}$ 。

\section{3 结语}

综上所述, 在露天铁矿开采过程中, 不但要对相关管理 措施进行强化, 还要在各采矿环节中落实科技研究工作, 也 只有对各项工作的有效落实, 才能保证露天采矿工作的顺利 开展。

\section{[参考文献]}

[1]姜景虎.露天铁矿采矿生产中相关问题的探讨[J]. 黑 龙江科技信息,2014,7(32):56-56.

[2] 廖成孟.大治铁矿露天转地下安全回采工艺的研究 [D].武汉科技大学, 2013,(03):72.

[3] 陈洪玉.露天铁矿采矿生产中的问题[J]. 山东工业技 术,2018,9(18):74.

[4]何贵元.刍议某露天铁矿采矿生产中常见的问题与对 策[J].低碳世界,2014,3(14):190-191.

[5]冯兴荣.露天铁矿采矿生产中的问题分析[J].经贸实 践,2017,4(12):207.

[6]马旭峰, 徐帅, 刘显峰. 眼前山铁矿露天转井下采矿方 法研究 [J].金属矿山,2013,8(5):37-39.

[7]章启忠.大冶铁矿深凹露天转地下开采的几个安全问 题研究[D].武汉科技大学,2014,(04):65. 